\title{
Electron attachment spectroscopy as a tool to study internal rotations in isolated negative ions
}

\author{
Stanislav A. Pshenichnyuk $\odot,{ }^{1, *}$ Alberto Modelli, ${ }^{2,3}$ Nail L. Asfandiarov $\odot,{ }^{1}$ Rustam G. Rakhmeyev $\odot,{ }^{1}$ \\ Mansaf M. Tayupov ${ }^{\circ},{ }^{1}$ and Alexei S. Komolov ${ }^{4}{ }^{4}$ \\ ${ }^{1}$ Institute of Molecule and Crystal Physics, Ufa Federal Research Centre, Russian Academy of Sciences, \\ Prospeкt Oktyabrya 151, 450075 Ufa, Russia \\ ${ }^{2}$ Dipartimento di Chimica “G. Ciamician,” Università di Bologna, via Selmi 2, 40126 Bologna, Italy \\ ${ }^{3}$ Centro Interdipartimentale di Ricerca in Scienze Ambientali, Università di Bologna, via S. Alberto 163, 48123 Ravenna, Italy \\ ${ }^{4}$ St. Petersburg State University, Universitetskaya Naberezhnaya 7/9, 199034 St. Petersburg, Russia
}

(Received 17 September 2019; revised manuscript received 2 November 2019; accepted 29 December 2019; published 4 February 2020)

\begin{abstract}
Electron-driven processes in the triclosan molecule are studied under gas-phase conditions using dissociative electron attachment (DEA) spectroscopy with the support of density functional theory calculations. Several decay channels of the short-lived (less than $17 \mu \mathrm{s}$ ) molecular anion of triclosan are associated with excitation of internal rotations of the phenyl rings around the $\mathrm{C}-\mathrm{O}$ bonds. This leads to production of a dioxin anion by elimination of a neutral $\mathrm{HCl}$ molecule or negatively charged hypochlorous acid and dibenzofuran as the neutral counterpart. These decays are accompanied by cleavage and formation of several covalent bonds and appear on the microsecond timescale as confirmed by detection of metastable anions. On the basis of the present and earlier findings, DEA spectroscopy demonstrates to be a suitable technique for studying internal rotations in negative ions, although quite differently from the experimental techniques-microwave and Raman spectroscopies-usually employed to study internal rotations in neutral molecules.
\end{abstract}

DOI: 10.1103/PhysRevResearch.2.012030

Understanding of internal rotations in molecular systems of different sizes is of importance from both the theoretical and the practical points of view [1,2]. For instance, the control of rotational motions of relatively small molecular groups driven either by light or by an electron flow allows to construct molecular machines which mimic the functions of their macroscopic analogs [3,4]. Complicated biological processes, such as the generation of adenosine triphosphate in mitochondria and protein folding as well as the dynamics and shape of polymeric molecules, are due to rotations of large molecular structures often linked with simple twisting about single chemical bonds [5,6]. Besides theoretical and modern computational approaches $[7,8]$, internal rotations in neutral molecules can be excited and studied under isolated (gas-phase) conditions by means of microwave spectroscopy $[2,9]$ to measure the energies of transitions between rotational states of polar molecules. Low-frequency rotations of nonpolar targets can be studied using Raman spectroscopy [10].

The present Rapid Communication attracts attention to the possibility of using substantially different and less common experimental means to study internal rotations in molecular systems bearing an excess electron, i.e., molecular negative ions. In fact, our previous results [11,12] show that rotational motion in isolated molecules can be initiated by

\footnotetext{
*Corresponding author: sapsh@anrb.ru
}

Published by the American Physical Society under the terms of the Creative Commons Attribution 4.0 International license. Further distribution of this work must maintain attribution to the author(s) and the published article's title, journal citation, and DOI. low-energy (0-15-eV) electron attachment via resonance mechanisms [13]. A dissociative electron attachment (DEA) study of dianilindoanthracene (DAA) [11] concluded that an incoming electron initiates rotational motion of (at least) one aniline substituent around a $\mathrm{C}-\mathrm{N}$ bond of the long-lived (mass-spectrometrically detectable) molecular anion as schematically shown in Fig. 1. Thereupon the so-formed molecular negative ion $\mathrm{DAA}^{-}$eliminates either the excess electron (during hundreds of microseconds) probably producing a rotationally excited neutral DAA molecule or an $\mathrm{H}_{2}$ neutral molecule, thus, leading to the interruption of a rotational motion due to the formation of a new $\mathrm{C}-\mathrm{C}$ covalent bond in the negatively charged fragment. A DEA study of decabromodiphenyl ether (DBDE) [12] showed that elimination of $\mathrm{Br}_{2}^{-}$from the short-lived (not detected mass-spectrometrically) $\mathrm{DBDE}^{-}$anion generates a neutral octabromodibenzofuran molecule, i.e., a structure that has no rotational degrees of freedom (see Fig. 1). In both cases, the interruption of rotation is associated with the formation of a diatomic species, neutral $\mathrm{H}_{2}$, or anionic $\mathrm{Br}_{2}^{-}$due to approaching hydrogen or bromine atoms under rotational motions.

The present Rapid Communication reports similar effects found in triclosan [(TCS), 2,4,4'-trichloro- $2^{\prime}$ hydroxydiphenyl ether], structurally close to DBDE (see Fig. 2). Therefore, besides the widely studied antibacterial properties and harmful effects $[14,15]$ of TCS, its molecular anion represents a suitable model to investigate the effects of internal rotational motions along its $\mathrm{C}-\mathrm{O}$ bonds. A notable difference relative to DBDE concerns the masses of the substituted phenyl rings so that their rotational structures are expected to be different. On the basis of the present findings, we put forward DEA spectroscopy as a new tool 


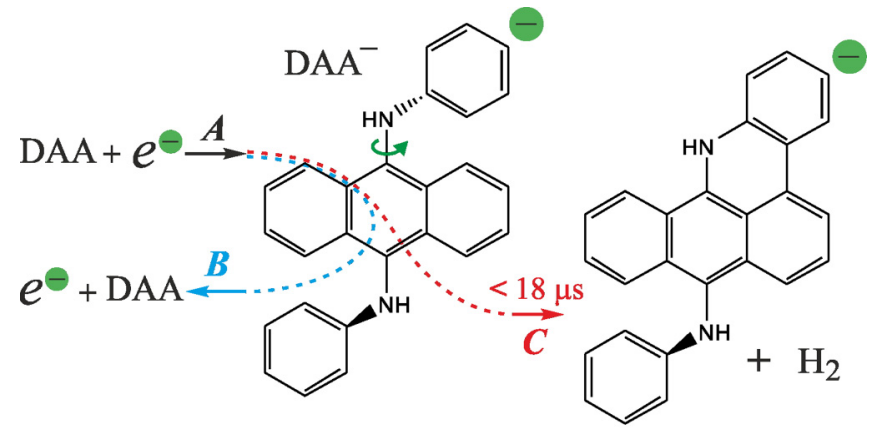

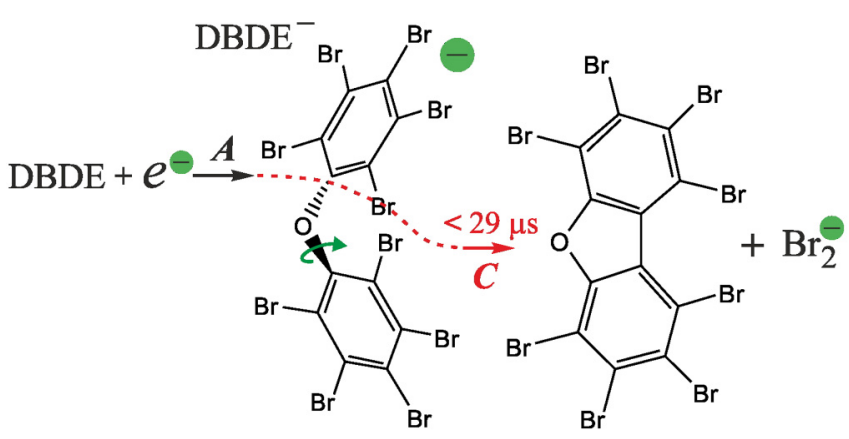

FIG. 1. Excitation of internal rotations (green bent arrows) by low-energy electron attachment (process $\boldsymbol{A}$, black lines) to DAA and DBDE; the long-lived molecular anion $\mathrm{DAA}^{-}$detaches the excess electron (pathway $\boldsymbol{B}$, blue line) during $100-400 \mu$ s depending on the initial resonant state; both rotating anions $\mathrm{DAA}^{-}$and $\mathrm{DBDE}^{-}$ can decay (pathway $\boldsymbol{C}$, red lines) on the microsecond timescale via elimination of a diatomic species and formation of a $\mathrm{C}-\mathrm{C}$ bond which prevents rotation.

to study rotations in molecular systems under accurately controlled energetic conditions, the whole process involving specific negative ion resonances [13]. Besides contributing to the understanding of operational laws of electron-driven molecular machines and biological applications, the present findings are of fundamental importance since they concern elementary transformations of isolated quantum systems containing a given amount of excess internal energy brought by the incoming electron.

The simplest reaction under study is $\mathrm{TCS}+e^{-} \rightarrow$ TCS $^{-} \rightarrow$ Fragments where TCS is a neutral target molecule and $\mathrm{TCS}^{-}$is its molecular temporary negative ion (TNI). Currents of mass-selected fragment anions formed by DEA to TCS as a function of incident electron energy are reported in Fig. 2 in order of decreasing intensity. Likely structures of the negative fragments, peak energies, and relative intensities of their yields are presented in Table I in order of decreasing mass numbers. We will briefly review a variety of (common) dissociative decay channels and the resonant states involved and then will focus on the most interesting decays associated with internal rotations in $\mathrm{TCS}^{-}$.

The B3LYP/6-31G(d) virtual orbital energies (VOEs) of the lowest empty $\pi^{*}$ and $\sigma^{*}$ molecular orbitals (MOs) of neutral TCS are listed in Table II. Empirical rules for the linear scaling of VOEs [16] (SVOE $=0.8065 \times \mathrm{VOE}+0.9194$ [17] and SVOE $=0.8111 \times \mathrm{VOE}+1.6097$ [18]) are used to predict the vertical attachment energies (VAEs) to $\pi^{*}$ and $\sigma_{\mathrm{C}-\mathrm{Cl}}^{*} \mathrm{MOs}$, respectively, i.e., the electron energies at which

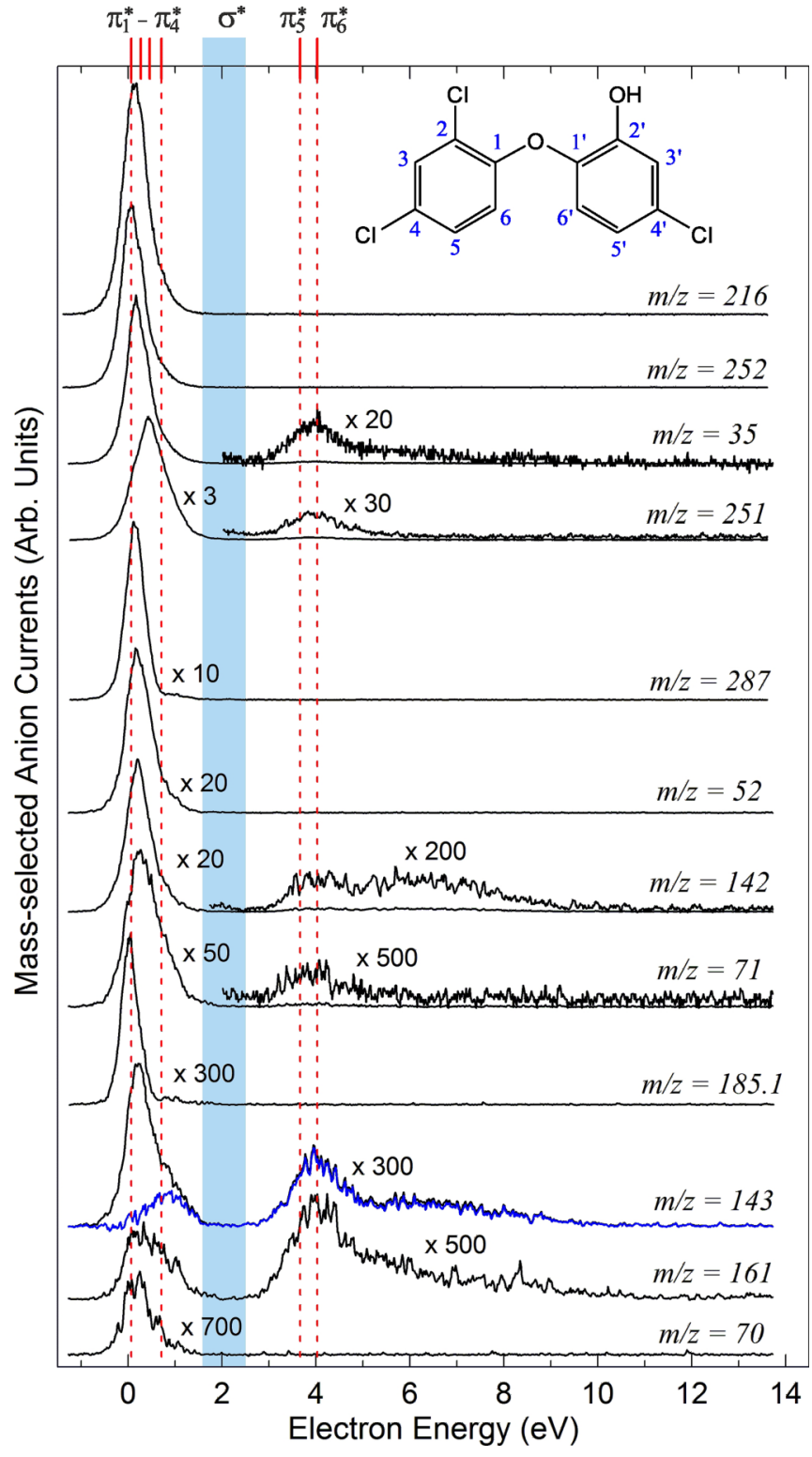

FIG. 2. DEA spectra of TCS (solid black lines); the blue curve indicates the $m / z=143$ signal after subtraction of isotopic contributions from $m / z=142$; predicted positions of the lowest unoccupied $\pi^{*}$ MOs (red vertical bars and dashed lines); predicted energy range of the lowest three $\sigma^{*}$ MOs (wide blue bar); molecular structure of TCS and atom position labeling.

the formation of TNI states occurs. The SVOEs of triclosan are reported in Fig. 2. It is clearly indicated that all signals observed below $1.5 \mathrm{eV}$ in the DEA spectra are associated with (possibly unresolved) contributions of shape resonances (SRs) [13] due to electron capture into the lowest four $\pi_{1}^{*}-\pi_{4}^{*}$ MOs. The predicted positions of the $\pi_{5}^{*}$ and $\pi_{6}^{*}$ SRs match the signals observed around $4 \mathrm{eV}$, the weak features at higher energies being ascribed to the formation of core-excited resonances [13]. There is no evidence for contributions to the DEA spectra from the three low-lying $\sigma^{*}$ MOs with mainly $\mathrm{C}-\mathrm{Cl}$ character.

The simplest DEA processes stem from cleavage of a single covalent bond. In the present case, they include the 
TABLE I. Likely structures of fragment negative ions observed in the DEA spectra of triclosan, peak energies $(\mathrm{eV})$, and relative intensities evaluated from the peak heights.

\begin{tabular}{|c|c|c|c|}
\hline$M / z$ & Anion structure & Peak energy & Relative intensity \\
\hline 287 & {$[\mathrm{TCS}-\mathrm{H}]^{-}$} & $\begin{array}{c}0.1 \\
0.9 \text { sh. }^{\mathrm{a}}\end{array}$ & 7.7 \\
\hline 252 & {$[\mathrm{TCS}-\mathrm{HCl}]^{-}$} & $\begin{array}{c}0.1 \\
0.3 \mathrm{sh} .\end{array}$ & 79 \\
\hline 251 & {$[\mathrm{TCS}-\mathrm{HCl}-\mathrm{H}]^{-}$} & $\begin{array}{c}0.1 \mathrm{sh}^{\mathrm{a}} \\
0.4 \\
3.9\end{array}$ & $\begin{array}{l}18 \\
3.7\end{array}$ \\
\hline 216 & {$[\mathrm{TCS}-2 \mathrm{HCl}]^{-}$} & $\begin{array}{c}0.1 \\
0.3 \mathrm{sh}^{\mathrm{a}}\end{array}$ & 100 \\
\hline 185.1 & $m *: 252 \rightarrow 216$ & $\begin{array}{c}<0.1 \\
1.0 \mathrm{sh}^{\mathrm{a}}\end{array}$ & 0.2 \\
\hline 161 & {$\left[\mathrm{TCS}-\mathrm{C}_{6} \mathrm{H}_{3} \mathrm{ClOH}\right]^{-}$} & $\begin{array}{c}0.3 \\
4.0 \\
\sim 6-9 \text { broad }\end{array}$ & $\begin{array}{l}0.1 \\
0.1\end{array}$ \\
\hline 143 & {$\left[\mathrm{TCS}-\mathrm{C}_{6} \mathrm{H}_{3} \mathrm{Cl}_{2}\right]^{-}$} & $\begin{array}{c}0.9^{c} \\
4.0 \\
\sim 6-9 \text { broad }\end{array}$ & $\begin{array}{l}0.1 \\
0.1\end{array}$ \\
\hline 142 & {$\left[\mathrm{TCS}-\mathrm{C}_{6} \mathrm{H}_{4} \mathrm{Cl}_{2}\right]^{-}$} & $\begin{array}{c}0.2^{\mathrm{b}} \\
4.0 \\
\sim 6-9 \text { broad }\end{array}$ & $\begin{array}{l}3.4 \\
0.1\end{array}$ \\
\hline 71 & $\mathrm{Cl}_{2} \mathrm{H}^{-}$ & $\begin{array}{r}0.2^{\mathrm{b}} \\
4.0\end{array}$ & $\begin{array}{c}1.4 \\
<0.1\end{array}$ \\
\hline 70 & $\mathrm{Cl}_{2}^{-}$ & $0.2^{b}$ & $<0.1$ \\
\hline 52 & $\mathrm{ClOH}^{-}$ & $0.2^{\mathrm{b}}$ & 3.6 \\
\hline 35 & $\mathrm{Cl}^{-}$ & $\begin{array}{r}0.2^{b} \\
4.0\end{array}$ & $\begin{array}{l}71 \\
1.0\end{array}$ \\
\hline
\end{tabular}

${ }^{\mathrm{a}}$ sh. means shoulder.

${ }^{\mathrm{b}} \mathrm{The}$ 0.2-eV peak is ascribed to contributions from resonances lying around $0.1-0.3 \mathrm{eV}$.

${ }^{c}$ Peak energy and intensity of the $m / z=143$ signal are estimated after subtraction of isotopic contribution from the $m / z=142$ signal (blue curve in Fig. 2).

formation of dehydrogenated species $(m / z=287)$ and chloride anions $(\mathrm{m} / \mathrm{z}=35)$ and cleavage of the O-C $\left(1^{\prime}\right)(\mathrm{m} / z=$ $161)$ and $\mathrm{O}-\mathrm{C}(1)(m / z=143)$ bonds. Table III reports the B3LYP $/ 6-31+G(d)$ total energies (relative to the neutral state) of the suggested fragment species to support our inter-

TABLE II. B3LYP/6-31G(d) VOEs and predicted positions of negative ion resonances-scaled VOEs (SVOEs)-for the neutral triclosan molecule in the gas phase. All values are in $\mathrm{eV}$.

\begin{tabular}{lrr}
\hline \hline Orbital & VOE & SVOE \\
\hline$\pi_{6}^{*}$ & 3.852 & 4.03 \\
$\pi_{5}^{*}$ & 3.394 & 3.66 \\
$\sigma_{3 \mathrm{C}-\mathrm{Cl}}^{*}$ & 1.088 & 2.49 \\
$\sigma_{2 \mathrm{C}-\mathrm{Cl}}$ & 0.548 & 2.05 \\
$\sigma_{1 \mathrm{C}-\mathrm{Cl}}^{*}$ & -0.011 & 1.60 \\
$\pi_{4}^{*}$ & -0.262 & 0.71 \\
$\pi_{3}^{*}$ & -0.565 & 0.46 \\
$\pi_{2}^{*}$ & -0.811 & 0.27 \\
$\pi_{1}^{*}$ & -1.048 & 0.07 \\
\hline \hline
\end{tabular}

TABLE III. B3LYP/6-31 $+\mathrm{G}(\mathrm{d})$ total energies $(\mathrm{eV})$ relative to the neutral ground state of triclosan. Zero-point energy (ZPE) corrected values are in parentheses.

\begin{tabular}{llc}
\hline \hline$M / z$ & Fragments (anion + neutral) & Relative energy \\
\hline 288 & Vertical TCS & \\
288 & Adiabatic TCS & $0.19(-0.19)$ \\
287 & {$[\mathrm{TCS}-\mathrm{H}]^{-}+\mathrm{H}^{\bullet}$} & $-0.92(-1.02)$ \\
252 & $\mathrm{I}^{-}+\mathrm{HCl}$ & $0.82(0.44)$ \\
216 & {$[\mathrm{I}-\mathrm{HCl}]^{-}+2 \mathrm{HCl}$} & $0.16(-0.18)$ \\
216 & {$[\mathrm{TCS}-2 \mathrm{HCl}]^{-}+2 \mathrm{HCl}$} & $2.14(1.68)$ \\
216 & $\mathrm{II}^{-}+2 \mathrm{HCl}$ & $3.88(3.35)$ \\
161 & $\mathrm{C}_{6} \mathrm{H}_{3} \mathrm{Cl}_{2} \mathrm{O}^{-}+\mathrm{C}_{6} \mathrm{H}_{3} \mathrm{ClOH}^{\bullet}$ & $0.04(-0.39)$ \\
143 & {$\left[\mathrm{TCS}^{-} \mathrm{C}_{6} \mathrm{H}_{3} \mathrm{Cl}_{2}\right]^{-}+\mathrm{C}_{6} \mathrm{H}_{3} \mathrm{Cl}_{2}$} & $0.49(0.31)$ \\
142 & {$\left[\mathrm{TCS}-\mathrm{C}_{6} \mathrm{H}_{4} \mathrm{Cl}_{2}\right]^{-}+\mathrm{C}_{6} \mathrm{H}_{4} \mathrm{Cl}_{2}$} & $0.35(0.18)$ \\
52 & $\mathrm{ClOH}^{-}+\left[\mathrm{TCS}-\mathrm{Cl}^{-}(2)-\mathrm{OH}^{-}\right.$ & $-1.56(-1.72)$ \\
52 & $\mathrm{ClOH}^{-}+\mathrm{III}$ & $4.18(3.85)$ \\
35 & $\mathrm{Cl}^{-}+\left[\mathrm{TCS}-\mathrm{Cl}^{-}(2)\right]^{\bullet}$ & $-1.05(-1.20)$ \\
35 & $\mathrm{Cl}^{-}+\left[\mathrm{TCS}-\mathrm{Cl}^{\bullet}(4)\right]^{\bullet}$ & $0.18(0.09)$ \\
35 & $\left.\mathrm{Cl}^{-}+\left[\mathrm{TCS}-\mathrm{Cl}^{\prime}\right)\right]^{\bullet}$ & $0.21(0.11)$ \\
\hline \hline
\end{tabular}

Note: Structures I (2,8-dichlorodibenzo-p-dioxin), II, and III (2,8dichlorodibenzofuran) are shown in Figs. 3 and 4.

pretation of their structures. For instance, decay of $\mathrm{TCS}^{-}$via elimination of $\mathrm{Cl}^{-}$from any ring position requires about 0.1 $\mathrm{eV}$ (see Table III) and coincides well with the peak energy $(0.2$ $\mathrm{eV}$ ) of the observed $m / z=35$ current (see Table I and Fig. 2). The calculated energy threshold for hydrogen abstraction from the $\mathrm{OH}$ group of $\mathrm{TCS}^{-}$is $0.44 \mathrm{eV}$, somewhat higher than the observed $[\mathrm{TCS}-\mathrm{H}]^{-}$peak energy. It likely means that part of the excess vibrational energy stored in $\mathrm{TCS}^{-}$is used to overcome the threshold to form the $m / z=287$ anion, whereas the thresholds calculated for the $m / z=161$ and 143 anions are in agreement with the corresponding observed signals. Cleavage of the $\mathrm{O}-\mathrm{C}(1)$ bond accompanied by $\mathrm{H}$ atom transfer from the $\mathrm{OH}$ group can be responsible for formation of very stable products, namely, the observed $\mathrm{m} / \mathrm{z}=142$ fragment anion and a closed-shell neutral molecule of metadichlorobenzene as its neutral counterpart.

A more complex DEA process generates the $m / z=52$ negative fragment, ascribed to $\mathrm{ClOH}^{-}$on the basis of analysis of isotopic contributions to the $m / z=54$ signal. Formation of $\mathrm{ClOH}^{-}$at an energy as low as $0.2 \mathrm{eV}$ (see Table III) is only possible when the neutral counterpart is stable enough to lower the total energy of the products. For instance, simple abstraction of a chlorine atom from $\mathrm{C}(2)$ and the $\mathrm{OH}$ group to give a triplet-state neutral counterpart is calculated to require a threshold of $3.85 \mathrm{eV}$, much higher than the observed $0.2-\mathrm{eV}$ peak energy. A suitable candidate for the neutral fragment is 2,8-dichlorodibenzofuran (structure III in Fig. 3) which leads to a negative calculated threshold. In this case, in agreement with the B3LYP6-31 + G(d) optimized geometries of TCS and $\mathrm{TCS}^{-}$, anion formation leads to rotation of the rings around the $\mathrm{O}-\mathrm{C}(1)$ and $\mathrm{O}-\mathrm{C}\left(1^{\prime}\right)$ bonds with a consequent reduction of the $\mathrm{Cl}(2)-\mathrm{HO}$ distance, thus, favoring: (i) the excision of a $\mathrm{ClHO}^{-}$negative fragment and (ii) the formation of a neutral closed-shell 2,8-dichlorodibenzofuran molecule as shown in Fig. 3. In this reaction, the number of cleaved bonds of the target molecule is equal to that of the bonds newly formed in the products. It, therefore, can be considered 


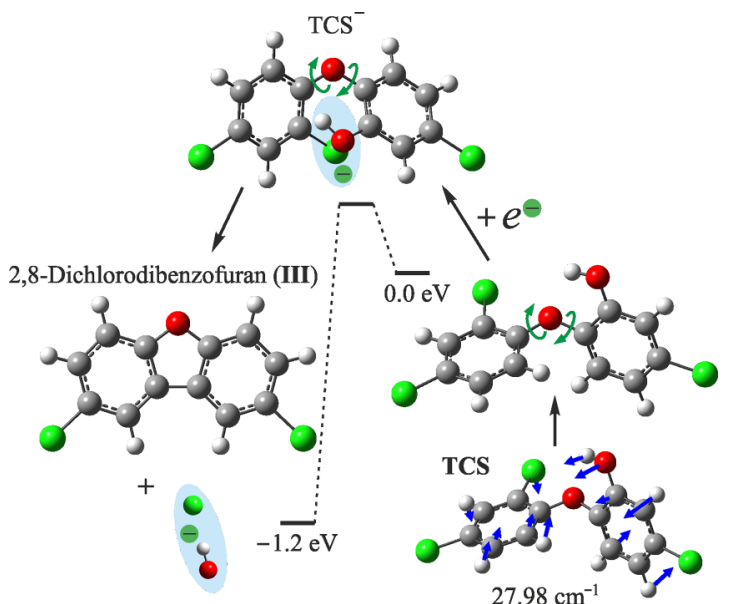

FIG. 3. Schematic of the formation of $\mathrm{ClOH}^{-}$and 2,8dichlorodibenzofuran by DEA to TCS via a hypothetical transition state of $\mathrm{TCS}^{-}$formed by rotation of both rings to move a negatively charged $\mathrm{Cl}$ atom and an $\mathrm{OH}$ group close to each other (blue ellipse); second normal vibrational mode likely responsible for initiation of the ring rotational motions and displacement directions of the atoms (dark blue arrows).

an isodesmic process as defined by Hehre et al. [19] except for the change in bond type.

In the present picture, the second normal vibration of TCS can be responsible for excitation of internal rotations in $\mathrm{TCS}^{-}$ as schematically shown in Fig. 3. This vibration has a low frequency [the B3LYP/6-31+ G(d) value is $27.98 \mathrm{~cm}^{-1} \approx$ $0.003 \mathrm{eV}]$, therefore, it is expected to be highly populated at the temperature of the experiment $\left(80{ }^{\circ} \mathrm{C}, k T \approx 0.03 \mathrm{eV}\right)$. However, the potential barrier for rotation of one ring along the $\mathrm{O}-\mathrm{C}\left(1^{\prime}\right)$ bond in neutral TCS is estimated [at the B3LYP/6-31 + G(d) level] to be about $0.3 \mathrm{eV}$ and cannot be overcome at $80^{\circ} \mathrm{C}$. But even zero-energy electron attachment leads to excess energy (equal to electron affinity) to be stored in $\mathrm{TCS}^{-}$that likely allows to initiate internal rotations.

The parent molecular negative ion $\mathrm{TCS}^{-}(\mathrm{m} / \mathrm{z}=288)$ is not observed under the present experimental conditions. However, the estimated adiabatic electron affinity of TCS is predicted to be high enough (1.02 eV, see Table III) to yield mass-spectrometrically detectable $\mathrm{TCS}^{-}$anions, the threshold value of adiabatic electron affinity to form long-lived (microseconds) molecular anions being estimated to be about $0.5 \mathrm{eV}[20]$. We, therefore, propose that $\mathrm{TCS}^{-}$decays by dissociation before its extraction from the collision cell, i.e., in a time shorter than the extraction time evaluated to be about $17 \mu$ s. It is reasonable to conclude that the most intense decay channels $(\mathrm{m} / z=216$ and 252$)$ derive from dissociation of $\mathrm{TCS}^{-}$before its acceleration into the mass-analyzing magnet.

It should be noted that the B3LYP/6-31 + G(d) calculations predict that the $\mathrm{C}(2)-\mathrm{Cl}$ bond in the optimized $\mathrm{TCS}^{-}$ geometry (reported in Fig. 4) is elongated to $2.595 \AA$ (to be compared with $1.745 \AA$ in neutral TCS) with most $(-0.576 e)$ of the excess negative charge on this chlorine atom. These computational results are strictly connected to the DEA properties of TCS: (i) $\mathrm{TCS}^{-}$in its optimized geometry is almost dissociated, thus, favoring the formation of all fragment species containing a $\mathrm{Cl}$ atom, and (ii) the behavior of $\mathrm{TCS}^{-}$ is complex since it contains two rotating rings and a heavy, weakly bound $\mathrm{Cl}$ atom. The latter point makes difficult the description of the transition states (such as shown in Fig. 3) since there are many pathways for the $\mathrm{Cl}$ atom to escape from $\mathrm{TCS}^{-}$ (either simply as $\mathrm{Cl}^{-}$, or within a larger fragment). Therefore, $\mathrm{TCS}^{-}$can be considered as a "rotationally activated weakly bound anionic complex." It is to be noted, however, that, in other cases, i.e., 2,4-dichlorophenoxyacetic acid long-lived molecular anions of chlorine derivatives can be observed despite their almost dissociated structure [21,22]. Since the signal of $\operatorname{TCS}^{-}(m / z=288)$ is not observed under the present
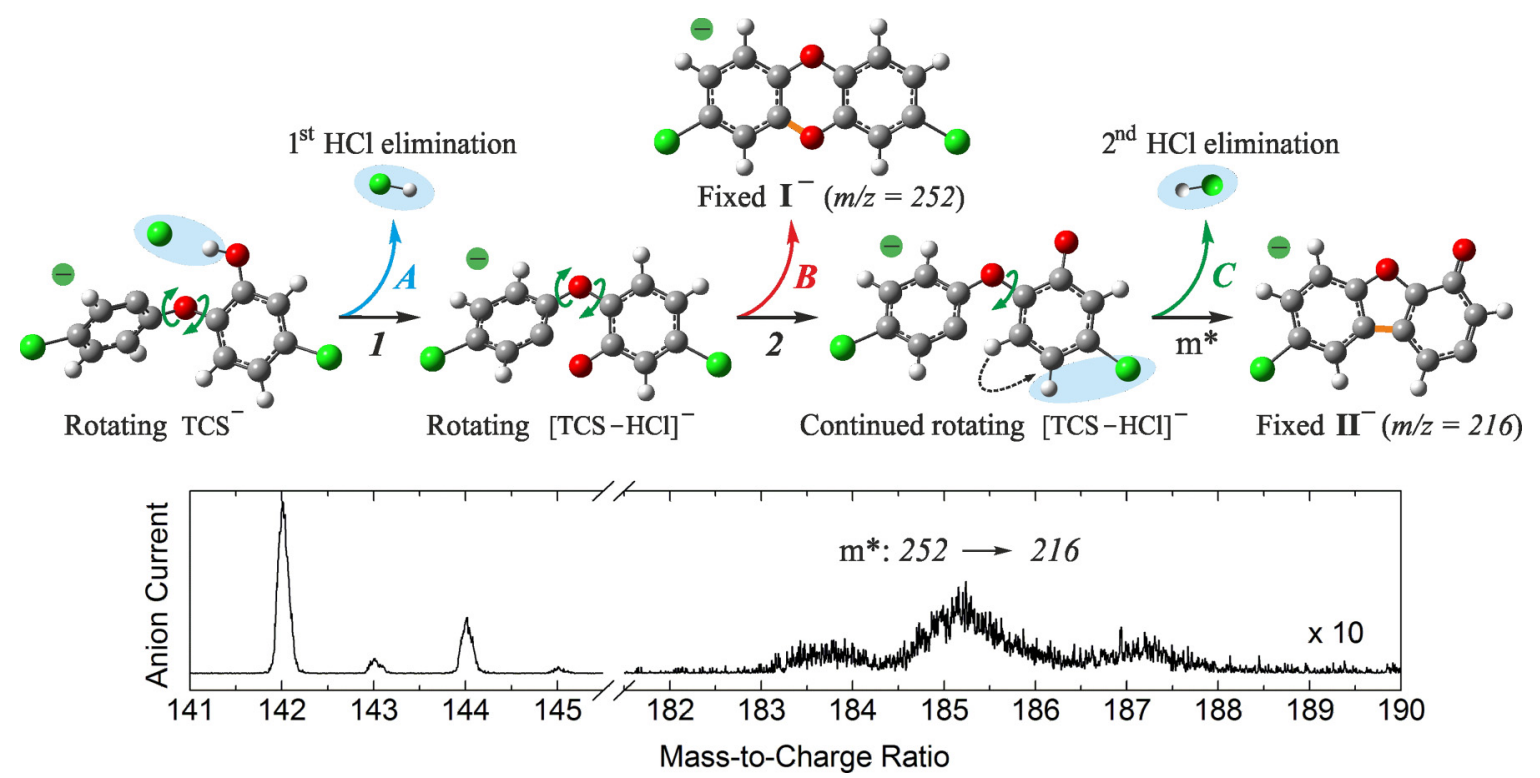

FIG. 4. Schematic of consecutive elimination of two neutral $\mathrm{HCl}$ molecules from $\mathrm{TCS}^{-}$; horizontal black arrows marked $\mathbf{1}$ and $\mathbf{2}$ correspond to, at least, one-half turn of the rings around the $\mathrm{C}-\mathrm{O}$ bonds; metastable (broad) anion peak at $\mathrm{m} / z=185.1$ in comparison with the normal signal at $m / z=142$ in the mass spectrum recorded close to zero energy of incident electrons. 
experimental conditions, its lifetime (with respect to both electron detachment and dissociation) is expected to be shorter than $17 \mu \mathrm{s}$, that is the estimated extraction time for $\mathrm{TCS}^{-}$from the collision cell.

The most intense signals, observed at $m / z=252$ and 216 , can reasonably be ascribed to elimination of one and two $\mathrm{HCl}$ molecules from $\mathrm{TCS}^{-}$, respectively, as reported in Fig. 4. Detection of a metastable anion peak at $\mathrm{m} / z=185.1$ (see Fig. 4) indicates that elimination of the second $\mathrm{HCl}$ molecule occurs consecutively, i.e., from $[\mathrm{TCS}-\mathrm{HCl}]^{-}$. The latter fragment can be formed at low energy provided that the first $\mathrm{HCl}$ elimination from rotating $\mathrm{TCS}^{-}$(pathway $\boldsymbol{A}$, blue arrow) is accompanied by the formation of a new $\mathrm{C}(2)-\mathrm{O}\left(2^{\prime}\right)$ bond (orange thick line) to produce the 2,8-dichlorodibenzo$p$-dioxin anion, observed at $m / z=252$ (pathway $\boldsymbol{B}$, red arrow). Some $[\mathrm{TCS}-\mathrm{HCl}]^{-}$anions continue rotating and are expected to follow pathway $\mathbf{2}$ that gives rise to the consecutive decay. To satisfy the energetic requirements (see Table III), the second $\mathrm{HCl}$ elimination from $[\mathrm{TCS}-\mathrm{HCl}]^{-}$(pathway $\boldsymbol{C}$, green arrow) must proceed via the formation of a $\mathrm{C}(6)-\mathrm{C}\left(6^{\prime}\right)$ bond (orange thick line) accompanied by migration of the $\mathrm{H}\left(6^{\prime}\right)$ atom (dashed arrow). This leads to production of the observed $m / z=216$ anion (metastable pathway $m^{*}$, black line), the calculated energy threshold being negative (structure II in Table III). Elimination of the first $\mathrm{HCl}$ molecule from $\mathrm{TCS}^{-}$ (pathway $\boldsymbol{A}$ in Fig. 4) requires excitation of internal rotational motion in $\mathrm{TCS}^{-}$, analogously to that required for generation of the $m / z=52$ anion (see Fig. 3) to bring the hydrogen and chlorine atoms close enough. Therefore, this decay occurs in kinetic competition with formation of the $m / z=52$ fragment, the latter, however, being much less probably as indicated by their relative intensities. The second $\mathrm{HCl}$ elimination from the $m / z=252$ (pathway $\boldsymbol{C}$ in Fig. 4) is also associated with rotational motion to promote generation of structure $\mathrm{II}^{-}$via formation of a $\mathrm{C}(6)-\mathrm{C}\left(6^{\prime}\right)$ bond. Consecutive elimination of two neutral $\mathrm{HCl}$ molecules from $\mathrm{TCS}^{-}$reported in Fig. 4 is found to be the only possible pathway to satisfy the energetic conditions for generation the $m / z=252$ and 216 fragment anions.

Finally, we note that the $m / z=161$ signal is also likely connected to internal rotations, whereas the $m / z=70$ and 71 anions are due to rearrangements often observed in molecules containing several chlorine atoms [21]. The present data lead to the following conclusions.

(1) Electron attachment to TCS allows to overcome the potential barrier to initiate internal rotations in $\mathrm{TCS}^{-}$, likely stimulated by low-frequency vibrational modes of neutral TCS.

(2) The formation of the most abundant fragments observed in the DEA spectra of TCS requires complex rearrangements of the initial structure that, in turn, are due to internal rotations. Since the rational quanta are small, a strong temperature dependence can be expected.

(3) DEA spectroscopy can be considered as a tool for detection of internal rotations in negative ions formed by resonance electron attachment via monitoring of negative fragments whose formation implies the occurrence of rotational motions.

(4) Modifications of the DEA equipment, such as implementation of an accurate control of the experimental timescale, are necessary to corroborate the above idea since analysis of the timescale and observation of metastable decays allow to characterize some features of the rotational motions involved.

(5) An additional challenge concerns the observation of analogous rotation-driven decay channels in simpler molecular structures (where rotational transformations initiated by low-energy electron attachment are less complex than in TCS) to avoid formation of weakly bound (partially dissociated) anion complexes so that the experimental findings can be supported by calculations of rotational barriers.

Experimental and computational methods. 1. DEA study in vacuo. A general overview of DEA spectroscopy may be found elsewhere [13,23,24] including a schematic and description of specific conditions $[25,26]$. Briefly, a magnetically collimated electron beam of defined energy was passed through a collision cell containing a vapor of the substance under investigation under single-collision conditions. A current of magnetically mass-selected negative ions was recorded as a function of the incident electron energy in the $0-14-\mathrm{eV}$ energy range. The electron energy scale was calibrated with the $\mathrm{SF}_{6}^{-}$signal at zero energy, generated by attachment of thermal electrons to $\mathrm{SF}_{6}$. The full width at half maximum of the electron energy distribution was $0.4 \mathrm{eV}$, and the accuracy of the measured peak positions was estimated to be $\pm 0.1 \mathrm{eV}$.

Metastable negative ions are detected as broad peaks in the mass spectrum and indicate a slow decay between the initial $\left(m_{1}\right)$ and the final $\left(m_{2}\right)$ negative fragments, i.e., the process $m_{1} \rightarrow m_{2}+$ neutral, which takes place in the acceleration region outside the collision cell [27]. In fact, the occurrence of fragmentation in this region requires a microsecond timescale. The presence of metastable peaks in a mass spectrum indicates a slow decomposition pathway of the initial state and supplies unambiguous information on the masses of both the initial $\left(m_{1}\right)$ and the final $\left(m_{2}\right)$ ions according to the relation $m^{*}=$ $m_{2}^{2} / m_{1}$, where $m^{*}$ is the apparent $m / z$ ratio of the broad metastable peak in the mass spectrum.

The substance under investigation (Sigma-Aldrich No. 93453) was evaporated at $50{ }^{\circ} \mathrm{C}$ (below the melting point at $55-57^{\circ} \mathrm{C}$ ), and the collision cell was held at the minimal accessible temperature $\left(80^{\circ} \mathrm{C}\right)$ due to heating from the hot filament, whereas triclosan is found to be thermally stable up to $150^{\circ} \mathrm{C}[28]$.

2. In silico methods. Density functional theory calculations were performed with the GAUSSIAN 09 set of programs [29]. Evaluation of the VOEs of the neutral molecule was performed using the B3LYP hybrid functional with the standard 6-31G(d) basis set. The vertical electron affinity was calculated as the difference between the total energy of the neutral and the lowest anion state, both in the optimized geometry of the neutral state using the standard $6-31+\mathrm{G}(\mathrm{d})$ basis set. The adiabatic electron affinity was obtained as the energy difference between the neutral and the lowest anion states, each in its optimized geometry. Regardless of particular difficulties encountered for the description of anionic states [30], it has been demonstrated $[31,32]$ that good linear correlations can be obtained between the VAEs measured in electron transmission spectroscopy [33] and the corresponding VOEs of the neutral molecules calculated with basis sets which do not include 
diffuse functions. The scaling parameters are different for $\sigma^{*}$ and $\pi^{*}$ MOs, and a more accurate correlation would result if "training" compounds were employed that were structurally closer to the subject molecule.
The work was performed with support from the Russian Science Foundation (Project No. 19-13-00021). A.M. is grateful to the Italian Ministero dell'Istruzione, dell'Università e della Ricerca for financial support.
[1] D. A. Long, Internal rotation: A historical perspective, J. Mol. Struct. 126, 9 (1985).

[2] C. C. Lin and J. D. Swalen, Internal rotation and microwave spectroscopy, Rev. Mod. Phys. 31, 841 (1959).

[3] S. Kassem, T. van Leeuwen, A. S. Lubbe, M. R. Wilson, B. L. Feringa, and D. A. Leigh, Artificial molecular motors, Chem. Soc. Rev. 46, 2592 (2017).

[4] H. L. Tierney, C. J. Murphy, A. D. Jewell, A. E. Baber, E. V. Iski, H. Y. Khodaverdian, A. F. McGuire, N. Klebanov, and E. C. H. Sykes, Experimental demonstration of a singlemolecule electric motor, Nat. Nanotechnol. 6, 625 (2011).

[5] P. Guo, H. Noji, C. M. Yengo, Z. Zhao, and I. Grainge, Biological nanomotors with a revolution, linear, or rotation motion mechanism, Microbiol. Mol. Biol. Rev. 80, 161 (2016).

[6] M. V. Volkenstein, The configurational statistics of polymeric chains, J. Polymer Sci. 29, 441 (1958).

[7] E. B. Wilson, Jr., The problem of barriers to internal rotation in molecules, Adv. Chem. Phys. 2, 367 (1958).

[8] N. Sadlej-Sosnowska, Energy barriers to internal rotation: Hyperconjugation and electrostatic description, J. Phys. Chem. A 107, 8671 (2003).

[9] D. W. Pratt, High resolution spectroscopy in the gas phase: Even large molecules have well-defined shapes, Annu. Rev. Phys. Chem. 49, 481 (1998).

[10] B. C. Norman, H. D. Lawrence, and E. W. Stephen, Introduction to Infrared and Raman Spectroscopy (Academic, San Diego, 1990).

[11] S. A. Pshenichnyuk, N. L. Asfandiarov, and A. V. Kukhta, Interruption of the inner rotation initiated in isolated electron-driven molecular rotors, Phys. Rev. A 86, 052710 (2012).

[12] S. A. Pshenichnyuk, G. S. Lomakin, and A. Modelli, Degradation of gas phase decabromodiphenyl ether by resonant interaction with low-energy electrons, Phys. Chem. Chem. Phys. 13, 9293 (2011).

[13] G. J. Schulz, Resonances in electron impact on diatomic molecules, Rev. Mod. Phys. 45, 423 (1973).

[14] A. B. Dann and A. Hontela, Triclosan: Environmental exposure, toxicity and mechanisms of action, J. Appl. Toxicol. 31, 285 (2011).

[15] K. N. Belosludtsev, N. V. Belosludtseva, K. S. Tenkov, N. V. Penkov, A. V. Agafonov, L. L. Pavlik, V. A. Yashin, V. N. Samartsev, and M. V. Dubinin, Study of the mechanism of permeabilization of lecithin liposomes and rat liver mitochondria by the antimicrobial drug triclosan, Biochim. Biophys. Acta, Biomembr. 1860, 264 (2018).

[16] P. D. Burrow and A. Modelli, On the treatment of LUMO energies for their use as descriptors, SAR QSAR Environ. Res. 24, 647 (2013).
[17] A. M. Scheer and P. D. Burrow, $\pi^{*}$ orbital system of alternating phenyl and ethynyl groups: Measurements and calculations, J. Phys. Chem. B 110, 17751 (2006).

[18] P. D. Burrow, G. A. Gallup, and A. Modelli, Are there $\pi^{*}$ shape resonances in electron scattering from phosphate groups? J. Phys. Chem. A 112, 4106 (2008).

[19] W. J. Hehre, L. Radom, J. A. Pople, and P. v. R. Schleyer, Ab Initio Molecular Orbital Theory (Wiley, New York, 1986).

[20] L. G. Christophorou, Electron-Molecule Interactions and Their Applications (Academic, Orlando, FL, 1984), Vol. 2.

[21] S. A. Pshenichnyuk and A. Modelli, Can mitochondrial dysfunction be initiated by dissociative electron attachment to xenobiotics? Phys. Chem. Chem. Phys. 15, 9125 (2013).

[22] S. A. Pshenichnyuk, A. Modelli, E. F. Lazneva, and A. S. Komolov, Role of resonance electron attachment in phytoremediation of halogenated herbicides, J. Phys. Chem. B 120, 12098 (2016).

[23] E. Illenberger and J. Momigny, Gaseous molecular ions, An Introduction to Elementary Processes Induced by Ionization, Steinkopff Verlag Darmstadt (Springer-Verlag, New York, 1992).

[24] V. I. Khvostenko, Negative Ions Mass Spectrometry in Organic Chemistry (Nauka, Moscow, 1981) (in Russian).

[25] S. A. Pshenichnyuk and A. Modelli, in Mitochondrial Medicine, edited by V. Weissig and M. Edeas (Springer Science + Business Media, New York, 2015), Vol. II, p. 285.

[26] S. A. Pshenichnyuk and A. S. Komolov, Dissociative electron attachment to anthralin to model its biochemical reactions, J. Phys. Chem. Lett. 5, 2916 (2014).

[27] J. H. Beynon, Mass Spectrometry and Its Application to Organic Chemistry (Elsevier, Amsterdam, 1960).

[28] H. N. Bhargava and P. A. Leonard, Triclosan: Applications and safety, Am. J. Infect. Control 24, 209 (1996).

[29] M. J. Frisch, G. W. Trucks, H. B. Schlegel, G. E. Scuseria, M. A. Robb, J. R. Cheeseman, G. Scalmani, V. Barone, B. Mennucci, G. A. Petersson et al., GAUSSIAN 09, Revision A.02 (Gaussian, Inc., Wallingford, CT, 2009).

[30] J. Simons and K. D. Jordan, Ab initio electronic structure of anions, Chem. Rev. 87, 535 (1987).

[31] D. Chen and G. A. Gallup, The relationship of the virtual orbitals of self-consistent-field theory to temporary negative ions in electron scattering from molecules, J. Chem. Phys. 93, 8893 (1990).

[32] A. Modelli, Electron attachment and intramolecular electron transfer in unsaturated chloroderivatives, Phys. Chem. Chem. Phys. 5, 2923 (2003).

[33] K. D. Jordan and P. D. Burrow, Studies of the temporary anion states of unsaturated hydrocarbons by electron transmission spectroscopy, Acc. Chem. Res. 11, 341 (1978). 